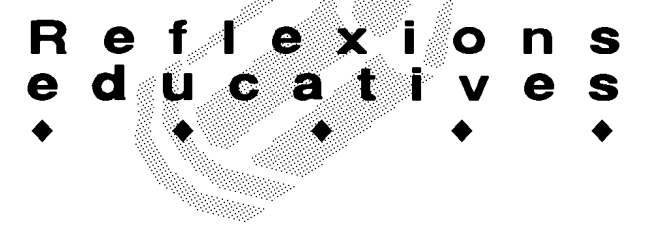

\title{
OPTIMITZAR LA CONVIVÈNCIA DES D'UNA ESCOLA INTERCULTURAL. PROGRAMA PER AFAVORIR EL DESENVOLUPAMENT ESCOLAR I SOCIAL DELS MARROQUINS
}

\author{
Enrique Fuentes Goyanes. Àrea de Teoria i Història de l'Educació. URV
}

\begin{abstract}
Un equip d'investigació cooperatiu
L'equip està format per professors i col-laboradors de les universitats de Barcelona i de la Rovira i Virgili i del col-legi d'Educació Infantil i Primària Milà i Fontanals, del barri del Raval a Barcelona.

Entre les finalitats dels membres de l'equip destaquen les de fer possible un discurs pedagògic en què les bases de la cultura catalana i les de les cultures d'immigració mantinguin les seves peculiaritats i comparteixin els valors humans de la cultura democràtica universal. L'equip el coordina la professora Maria de Borja (UB) i hi participen l'àrea de Teoria i Història de l'Educació de la UB (Montserrat Fortuny) i l'àrea de Teoria i Història de l'Educació de la URV (Enrique Fuentes).
\end{abstract}

\section{Educació i interculturalitat}

L'educació no soluciona les noves realitats ni els problemes de la immigració, però aprofita la diversitat cultural per fer veure que la pluralitat cultural enriqueix les persones i l'escola si aconsegueix que els ciutadans -que d'infants experimenten la riquesa de la diversitat $i$ el respecte per la diferència- relativitzin el que és propi, exercitin els punts de vista diferents, valorin les persones per elles mateixes, reflexionin sobre l'esencial $\mathrm{i}$ l'accidental dels éssers humans... Si aquests processos s'han viscut a l'escola és probable que s'arribi a adult sense por a la diferència i amb compromís per la solidaritat i defensa de la convivència, convençuts que el coneixement de l'altre facilita el treball cooperatiu obert a totes les idees.

\section{Pla de treball. Agenda d'investigació}

Al juny del 2000 ens vam reunir per realitzar el projecte d'intervenció escolar que, de forma progressiva i d'acord amb la Inspecció Tècnica, tindria una actuació de dos anys, en la seva primera fase, fent un seguiment dels nens i nenes de primer i segon de primària successivament.
A la programació, dissenyada d'acord amb unes pautes teòriques concretes, experimentaríem una sèrie d'activitats educatives i materials de suport. Segons els resultats aconseguits, i també d'acord amb l'autoavaluació de la professora de l'aula i d'un professor del centre, que faria d'observador extern, consensuaríem el seu valor didàctic i la seva eficàcia instructiva per poder difondre i aplicar a altres escoles i centres educatius.

Durant l'estiu del 2000 vam fer una revisió de textos sòcioantropològics, i d'articles que definien diferents projectes d'interculturalitat. Així mateix vam estudiar les possibilitats de transversalitat que ens ofereix el PEC d'Educació Primària, de la mateixa manera que els suports institucionals per introduir noves activitats al currículum del centre d'acord amb la proposta de la Llei d'Educació d'integrar les característiques de la diversitat social a l'escola.

Al mes de setembre vam consensuar amb la direcció del CEIP Milà i Fontanals i amb les professores de primer de primària les possibilitats i els límits de la nostra intervenció.

A l'octubre vam començar el desenvolupament del programa. Al gener del 2001, avaluats els primers resultats i diverses contingències i dificultats, vam reduir les actuacions a una de les dues aules de primer curs $i$ vam començar a potenciar la resolució de conflictes al pati i les perspectives que les activitats lúdiques i recreatives ens brinden per veure els avenços en la comunicació verbal i no verbal i la tolerància amb els diferents grups i personalitats que es reflecteixen en aquestes dinàmiques més espontànies.

L'estudi de la contingència de l'educació escolar enfront de l'acció educativa o la precarietat en què es troben algunes famílies ens va fer proposar-nos una obertura dels objectius de la investigació cap a l'àmbit paraescolar de l'AMPA, a partir del segon trimestre.

Al juny del 2001 donem per finalitzat el treball del primer any i ens proposem, després de l'estudi del 


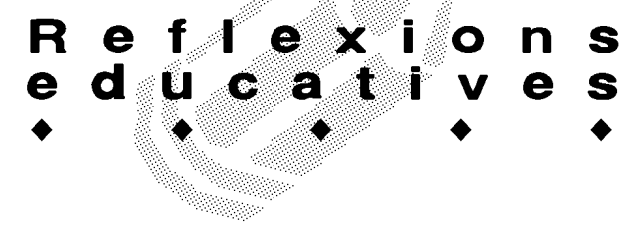

context social del barri i els resultats positius de l'experimentació, dissenyar el pla d'actuació per al curs 2001/ 2002 , integrant nous col-laboradors, activant nous espais temporals $\mathrm{i}$ desenvolupant noves activitats de primària $\mathrm{i}$ secundària.

\section{Plantejaments teòrics per a una intervenció educativa intercultural. Les bases antropològiques de la co- municació entre cultures}

L'aprenentatge cultural queda reflectit en el sistema de comunicació personal i social des de fa més de cinc dècades. Margaret Mead (1953) diu al respecte: "Todo comportamiento cultural tiene su origen en hombres que no solamente se escuchan, hablan y se comunican entre ellos por medio de palabras, sino que también utilizan todos sus sentidos, de forma igualmente sistemática, para ver y proyectar lo que ven en formas concretas -diseño, costumbre, arquitectura- y para comunicarse a través de la percepción mutua de imágenes visuales; para gustar, sentir y estructurar sus capacidades de la manera que la cocina y forma de comer de un pueblo puede ser tan distintiva y organizada como un lenguaje".

Uns anys més tard, Jakobson (1963) va proposar un estudi dels missatges que hem de desxifrar entre tres cercles: El cercle de la lingüística, els missatges verbals: català, castellà, àrab, berber, etc. El cercle de la semiòtica, l'estudi de comunicació de tot tipus de missatge incloent els no verbals. El cercle de la ciència de la comunicació, que inclou lingüística, antropologia i sociologia principalment.

La comunicació no se centra ni en la llengua ni en la parla, sinó en una sèrie d'actituds psicològiques i legals entre les quals hi ha la tolerància, la solidaritat i la llei.

De la teoria freudiana recollim que solament certs aspectes de la comunicació poden accedir a la consciència dels participants; altres poden ser oblidats 0 refusats.

La inconsciència és una necessitat de l'economia de l'esforç. Els canals de la comunicació tendeixen a evitar les pertorbacions, tant des del racional -el mestre o la mestra evita canvis-, o des de l'emotiu -al nen/a no li agrada que el renyin-. L'inconscient és el dipòsit dels materials refusats, l'origen de la ira, del racisme, del desànim que genera una baixa de l'autoestima, etc.

Aquestes bases teòriques ens permeten comprendre els conflictes personals dels petits escolars per mitjà de les anotacions del diari de la mestra, i veure que l'absència de la classe, l'escàs interès pels continguts, etc., reflecteixen la falta d'empatia, però sobretot, que la seva adaptació familiar és el seu més alt grau de preocupació i no el fet d'estar escolaritzat. Quan l'ambient escolar és gratificant, el seu sistema de comunicació s'utilitzarà per solucionar la incomunicació familiar.

"El nen porta un obsequi a la mare fet a classe; aquesta el llença a les escombraries". Creu que, a l'escola, la mestra li està robant el seu fill.

\section{El context de l'aprenentatge social i la cooperació necessària}

Un context d'aprenentatge és un espai i àmbit estructurat, d'intercanvi entre dues persones o cultures.

Els esdeveniments escolars que hem estudiat i les alternatives didàctiques que hem utilitzat ens permeten entendre l'escola: aula, pati, famílies, com un context. Els estímuls positius, les reaccions de satisfacció i els reforços verbals i no verbals que potencien l'autoestima, i marquen el camí del que "creiem que va bé", poden semblar que estan diversament plantejats, però constitueixen un tot interrelacionat i estructurat.

Gràcies a les dades experimentals sabem com es va produint l' estructuració dels coneixements i com varia la conducta dels subjectes.

Però el foment d'una educació bàsica de l'intercanvi i la tolerància no és fàcil ni progressiu, té dificultats i regressions, necessita el reforç de l'èxit no solament de l'escola sinó també dins de la societat que l'acull, l'entorn del barri, la població..., en el nostre cas, Catalunya.

\section{La revinculació i el projecte de viure en un ambient gratificant}

Per a una educació de qualitat que estigui valorada als ulls dels nous ciutadans no europeus, els esforços per una educació pública en la diversitat culturalhan de comptar i s'han de complementar amb accions que els assegurin un futur estable que depengui tant del nivell instructiu com de la seva regulació i exercici dels drets civils generals, inclosa la inserció laboral.

Segons experiències d'altres països, una acció civil afirmativa ha de suposar:

- Un desenvolupament curricular flexible que permeti la readaptació progressiva.

- Crear una atmosfera d'aprenentatge positiva que millori l'autoestima, valori la seva cultura i personalitat.

- Desenvolupar un programa complet, no sols lingüístic, que permeti passar per tots els nivells educatius, l'ensenyament superior inclòs, i desenvolupi el potencial individual, físic, emocional i els vincles socials del seu grup cultural i dels grups diversos del context.

- Assegurar l'aprenentatge d'una professió bàsica que permeti la seva integració laboral.

- Potenciar la creativitat del subjecte i totes les 


\section{$R$ e f e e $\mathbf{x}^{\prime}$ i $n$ s \\ e d u c a ti ves}

seves aptituds.

- Establir i mantenir una comunicació efectiva amb les famílies.

- Mantenir i exigir un barri saludable, segur i dotat de serveis suficients.

La diversitat cultural dels pobles i la llibertat d'expressió de les idees o les creences són indispensables per a un aprenentatge sociaöefectiu i pacífic, en el qual els nens/es tenen el dret a créixer amb seguretat, salut $i$ respecte per la seva identitat.

\section{Principis de cooperació amb el centre escolar}

- Adaptació a les normes pactades amb el centre.
- Flexibilitat en dies i horaris, i en la voluntat de col-laboració dels subjectes.

- Selecció de les activitats i de la seva continuïtat segons criteri de la mestra.

- Individualització de certes tasques per veure el grau d'assimilació segons cada cas.

- Varietat d'activitats d'aprenentatge elaborades per l'equip per fer-ne una selecció.

- Socialització dels materials degudament presentats per a ús indiscriminat.

Tipus d'activitats

a) Conflicte i discussió.

El primer material emprat va ser un vídeo-conte de

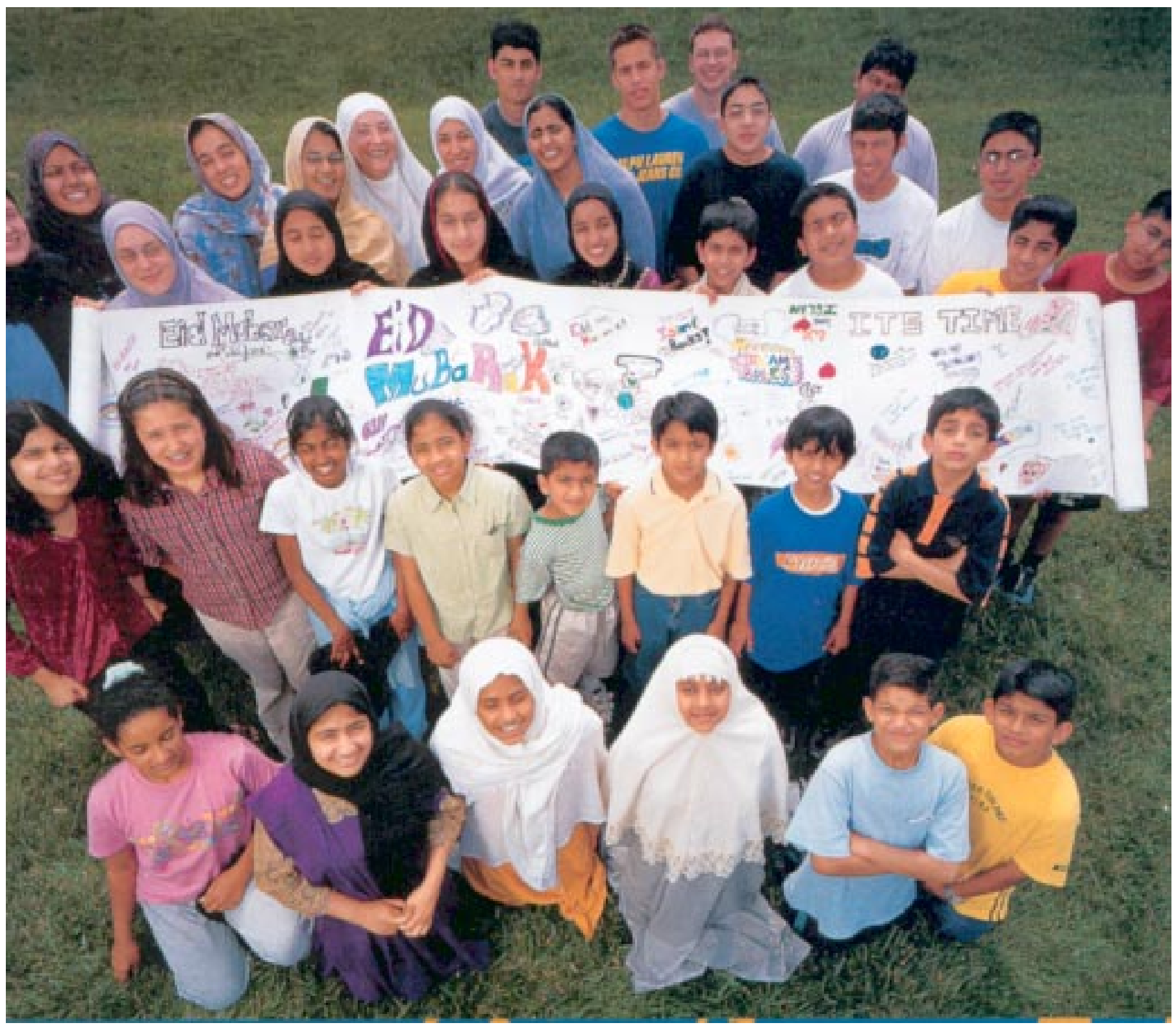




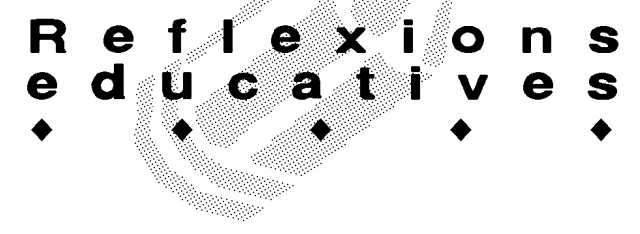

les aventures de la princesa Sherezade.

El conte es desenvolupa en ambients multiculturals àrabs. Els protagonistes principals són una princesa jove, un nen entremaliat $\mathrm{i}$ amb poders, el geni de la làmpada.

La sèrie té una cançó amb bon ritme que els nens $i$ nenes poden aprendre amb gust.

Es va utilitzar una versió en català de TV3 d'una producció de la televisió francesa.

Aquesta experiència va desencadenar múltiples activitats de comprensió lingüística i d'expressió verbal i no verbal, així com el desbloqueig d'alguns nens/es per una major identificació amb els personatges... imaginari col-lectiu.

Activitats derivades: Sessions de discussió sobre les històries i el seu significat, metacognició; expressió i ritme, musicalitat... connexió amb activitats lúdico-recreatives; formulació d'un vocabulari bàsic en català per centres d'interès: animals del circ, vestits, menjars, etc.

\section{b) Aprenentatge cooperatiu}

Es van proposar diversos jocs de l'obra "Juego cooperativo y socialización en el aula. Un programa de juego amistoso, de ayuda y cooperación, para el desarrollo socio-afectivo en niños de 6 a 8 años", de Maite Garaigordobil (1992).

Es van seleccionar les diferents modalitats dels jocs: de presentació, de comunicació verbal i no verbal, de donar i rebre ajuda, de confiança, de cooperació i cooperatius d'expressió dramàtica.

Es va fer una adaptació d'aquests jocs a situacions relacionades amb els costums dels pobles àrabs $i$ islàmics.

\section{c) Ensenyança directa}

Pel que fa a la Llengua Catalana: S'ha realitzat un vocabulari bàsic d' imatge i paraula digitalitzant imatges del vídeo de Sherezade segons els centres d'interès. També s'han seleccionat imatges complexes digitalitzades per associar amb frases senzilles que permetin fer un seguiment seqüencial d'una història.

Pel que fa a la cultura Islàmica i marroquina: S'ha fet, a proposta de la mestra, una selecció d'imatges de les bases culturals dels pobles islàmics i una altra de la cultura popular i civil marroquina.

La mestra va fer el seu propi pòster del seu viatge al Marroc. Amb això els nens/es la van identificar més dins del context que volíem revaloritzar.

d) Comprensió interpersonal i expressió artística

S'ha fet una selecció de contes il.lustrats amb escenografies àrabo-islàmiques. Es prepara una selecció de vídeos amb temes anàlegs. Es pretén fer uns contes il.lustrats per a l'alumnat de cursos superiors per a una interacció educativa entre diversos nivells que amplii l'interès d'altres classes pel disseny intercultural.
Justificació didàctica del conte oral i audiovisual

La literatura -en els seus diversos llenguatges; oral, escrit, visual- és un dels principals instruments de culturalització perquè interpreta i reelabora la realitat. En totes les cultures s'han produït contes o relats curts $i$ imaginaris que han perdurat en el temps.

El conte a les diferents cultures connecta d'una manera natural els infants amb la cultura de la qual forma part. Per altra banda, hi ha una coincidència de trets comuns que presenten contes creats per comunitats allunyades entre si.

Els contes faciliten coneixements sobre herois, mites, ideals i conflictes de la cultura que els ha elaborat. Ajuden a incorporar $\mathrm{i}$ assumir la cultura a què pertanyen col-laborant en la construcció de la pròpia identitat i en la valoració de la cultura dels companys.

Visualitzar, escoltar, llegir o explicar contes contribueix al desenvolupament de diferents capacitats relacionades amb diferents àmbits. La vessant afectiva del conte ajuda a desenvolupar la vida emocional al fer referència als sentiments humans, provoca l'interès dels infants i els capacita per mantenir l'atenció durant períodes de temps cada cop més llargs.

\section{Selecció i adequació de jocs}

Dins el treball realitzat a l'aula s'han utilitzat jocs per adquirir habilitats, estratègies, conductes prosocials... S'han extret molts d'ells amb petites modificacions de la tesi presentada per Maite Garaigordobil: Juego cooperativo y socialización en el aula. Un programa de juego amistoso, de ayuda y cooperación, para el desarrollo socio-afectivo en niños de 6 a 8 años.

Els jocs es divideixen en sis blocs: Jocs de presentació; jocs de comunicació verbal i no verbal; millora dels hàbits d'escolta; jocs de donar i rebre ajuda; jocs de confiança; jocs de cooperació i jocs cooperatius d'expressió dramàtica. Els jocs de presentació tenen per finalitat facilitar el coneixement entre els membres del grup, o sigui que s'apliquen a les primeres sessions del treball.

\section{Bases didàctico-pedagògiques de l'educació inter- cultural}

Les bases teòriques de la societat multiètnica $i$ pluricultural ens presenten les persones que han de viure entre dos sistemes culturals, sotmeses a una forta dualitat i lligades a un doble vincle emocional i pràxic. Els nens són els més afectats per aquestes tensions viscudes a les llars, amb la seva cultura minoritària, i a l'escola amb unes pràctiques d'aprenentatge generalistes. Així doncs, l'educació intercultural tendeix a mitigar la pressió d'aquesta divergència.

Per una part utilitza el reforç emocional, vinculant-lo 


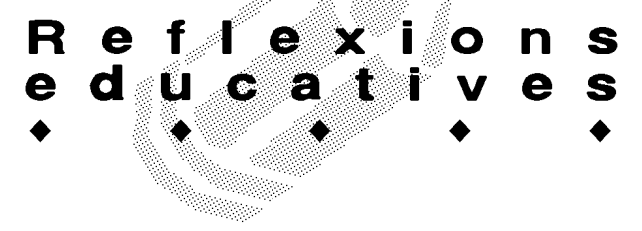

amb alguns coneixements i valors de la cultura dels seus pares.

També potencia l'associació, és a dir, considera que molts elements que semblen diferents són en la pràctica els mateixos a les diferents nacions i cultures. Per exemple, un instrument musical és diferent si és un tambor a l'Àfrica, un Ilaüt a l'Aràbia, o uns platerets a la Xina, però tots fan música, o tots es reuneixen en una orquestra que toca peces universals. Mitjançant la presentació d'aquests elements simples, utilitzant narracions i cançons, els nens els van acomodant entre els seus sabers, i és per mitjà del joc que comencen la seva praxi. Els mestres repetiran cadascun d'aquests elements en distintes situacions: conte, joc, conversa, dibuix... aconseguint que el nen vagi associant i aplicant el nom de l'objecte al sistema lingüístic escolar i familiar.

A l'integrar-lo en un sistema personal de comunicació, anirà fent transferències que li permeten una acomodació del coneixement après a les activitats de la seva vida quotidiana familiar i escolar, fins i tot dur a terme amb eficàcia una anàlisi dissociativa i diversificar el seu coneixement aplicant un bilingüisme o un sincretisme cultural, a casa i a l'escola.

Aquests principis de la didàctica són els que de forma sistemàtica hem emprat en l'experiència a l'aula de primer de primària de l'escola Milà i Fontanals.

Un dels objectius fonamentals era el coneixement pràctic de la llengua catalana. Per aconseguir que els nens anessin aprenent el nou idioma en una classe on hi havia diferents nens d'origen àrab, paquistanès, hispà i molt poca presència de nadius que per la pressió del grup reforcessin l'aprenentatge de la llengua pròpia, l'esforç de la motivació era imprescindible. Vam escollir un conte visual sobre la princesa Scherezade, que contenia diferents històries, i una cançó que es repetia dues vegades a cada episodi. Les històries, com la pròpia diversitat dels nens, succeïen en diferents països i amb diferents objectes i situacions, però molts d'aquests elements també els trobem en altres exercicis i contes, i sobretot en els jocs que havíem escollit per potenciar la solidaritat, l'amistat, la cooperació i l'acceptació de la diferència com a normalitat en la convivència cívica intercultural. El reforç i la transferència es produïen eficaçment, com vam anar comprovant al llarg del programa.

\section{L'expressió verbal i no verbal en l'adquisició de destreses comunicatives \\ La cancó de Scherezade}

Aquesta cançó en català amb certes paraules complicades, com el mateix nom de la princesa oriental, amb el ritme i la repetició i amb la transcripció en petites frases entrelligades per permetre la seva ordenació i associació verbal-escrita, va permetre la memorització i va incidir en la prelectura global i analítica.

\section{L'episodi del Geni Glu}

En aquest episodi un personatge dolent vol robar-li a la princesa una làmpada que conté un geni meravellós. El geni Glu té la plasticitat i adaptabilitat del xiclet, pot adoptar diferents formes i infinitat de moviments. Entre els jocs que utilitzem per potenciar la capacitat d'atenció i escolta i el control emocional, també hi ha el del "xiclet" que als nens els agrada especialment. Ambdues situacions s'unien per transferir aprenentatges psicomotors i millorar les relacions espacials i temporals tan necessàries per a una etapa prelingüística i per a la disciplina escolar.

Al conte apareixen uns deu animals diferents, que utilitzats en làmines individuals van potenciar un vocabulari bàsic imatge-paraula fonamental per produir sèries encadenades de paraules per recordar i dir. A més es podien introduir aleatòriament altres elements, vestits, flors, menjar... que utilitzaríem més tard per formar noves sèries de paraules, totes elles fàcils de transferir a situacions quotidianes dels diferents models culturals de les famílies d'aquests nens i nens.

Al conte hi ha una síntesi de situacions que apareixen en altres històries: la làmpada d'Al-ladí, el tresor amagat d'Alí Babà, la catifa voladora, etc. A més, aquests elements de fantasia són els que hem utilitzat per fer adaptacions de jocs generals a les peculiaritats de la cultura islàmica, com són: animals del món, estàtues de sorra, catifa voladora i buscar sabates. Apareixen unes paraules que a les sessions d'educació moral ajudaran perquè la mestra pugui conèixer el sistema de valors en què s'educa el nen/a a la seva casa: per exemple, enveja, mentida, gelosia, conspiracions, amistat, ajuda... Altres elements potencien el coneixement precientífic: fer ploure, màgia, un tro, agafar un constipat, allargarse...

\section{Episodi de les tres princeses}

En aquest episodi és on els nens han pogut trobar més motivació per a la pràctica de les relacions interculturals i per associar elements de les diferents cultures i transferir-los eficientment en la seva praxi comunicativa i en la formulació de judicis de valor que repercuteixen a millorar la seva autoestima: diferents però iguals en possibilitats. L'episodi es presenta en un palau de l'Àfrica subsahariana amb ambientació i situacions pròpies d'aquests pobles.

És una comparació visual i animada, amb gran sentit de l'humor, de les cultures àrab, xina i negrafricana. Una reina de l'Àfrica busca núvia per al seu fill, que està enamorat de la filla pobra del jardiner, Malika, que en 


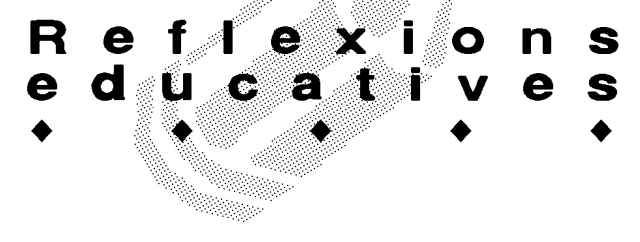

àrab significa reina. El noi està dominat per dues reines: una mare i una esposa (molt freudià).

S'envia un ban a tots els països perquè es presentin princeses $\mathrm{i}$ el príncep esculli (això encara passa als països més avançats d'Europa com en el nostre, no és un conte). Podem veure cada princesa amb diferents vestits, instruments, i fent gala de les seves habilitats... que ja coneixíem i ara poden ser comparats i valorats.

Scherezade viu en un palau àrab, amb columnes, arcs de ferradura i toca un llaüt. La princesa Awa viu en una cabana d'un arbre com Tarzan, vesteix com una pantera i balla. La princesa Li està a la Xina en un palau de bambú, a més sap kàrate, té caderneres, coses molt maques, màquines molt útils, $i$ arriba amb els seus monjos del Tibet que toquen platerets i trompetes. El palau africà és de fang molt decorat amb moltes escultures i rodejat d'un mercat on hi ha de tot, i un africà com aquí a la platja ven ulleres.

Ha de buscar objectes per regalar a la reina. Una catifa voladora, un mirall. Un dels jocs que potencia la identitat $i$ autoconcepte utilitza el mirall, $i$ ha resultat eficaç per a la integració de la diferència. Aquest mirall el troben en una cova on molts personatges estan adormits per efectes màgics. S'associa el joc de les estàtues de sorra que prenen vida. També porten uns polsets màgics que els dóna una bruixa bona que salven el príncep de la melangia i fan que prengui les seves pròpies decisions.

\section{Aprenentatge global}

El nostre programa es basa en la combinació de jocs i de contes que estimulen la comprensió i expressió verbal i no verbal. Hem presentat aquests continguts gradualment en sessions estructurades per temes de la motivació i la integració dels interessos individuals i culturals dels nens i nenes del grup classe, amb alumnes molt diferents en els àmbits intel-lectual, emocional i social.

Hem seleccionat jocs i contes que permetin el reforç, la reiteració, la memorització i les associacions per a la pràctica intercultural.

Els materials utilitzats són:

- Vídeo dels contes de Scherezade.

- Jocs adaptats a models culturals afroasiàtics: animals del món, la camella blanca, estàtues de sorra, el xinès que parla, la catifa voladora, viatges a llocs meravellosos, on són les sabates, a la porta de la mesquita, casa, aula, etc.

- Jocs per aplicar coneixements generals i desenvolupar tècniques comunicatives: aquest és el meu amic, el gest, tarja de visita, controla el teu riure, el xiclet, el mirall, coses bones dels meus companys, l'estàtua.
La forma d'aprensió d'aquesta estratègia intercultural es mèrit de les professores que han sabut distribuir-lo progressivament i reiteradament d'acord amb les pautes d'avaluació contínua que anàvem encadenant l'equip d'investigació i els professors involucrats.

El resultat queda confirmat per:

- L'informe d'avaluació externa del centre.

- La memòria de classe de la mestra.

- Les observacions generals i individuals de les investigadores a l'aula i al pati.

- L'anàlisi dels dibuixos i treballs dels nens que marquen els nivells de formació.

- La valoració sistemàtica i global dels resultats d'acord amb els objectius marcats al projecte.

Per tot això creiem, i es pot comprovar, que en les condicions psicoculturals i socials en què es produeix l'escolarització dels nens neociutadans de Catalunya, sense treure mèrit a altres projectes d'adaptació 0 aplicació del PEC, aquest model que hem assajat dóna resultats positius, sense deixar de produir els efectes generals de l'escolaritat primària bàsica a Catalunya, inclosa satisfactòriament, en la seva dimensió progressiva, la normalització lingüística. Per tant, d'acord amb aquestes bases pedagògiques i didàctiques interculturals, creiem indispensable continuar i ampliar el projecte a tots els nivells d'escolarització, així com generalitzarlo a altres centres educatius.

\section{Referències bibliogràfiques}

BATESON, C. La nueva comunicación. Edit. Kairós. Barcelona. 1987.

FUENTES, E. i COMES, G. La escolarización de niños magrebies en Tarragona. Jornadas de Educación Especial. URV. Tarragona. 1993.

GARAIGORDOBIL, M. El juego y desarrollo infantil. Edit. Seco Olea. Madrid. 1990.

JAKOBSON, R. Essais de Linguistique genèrale. Edit. Minuit. París. 1963.

MEAD, M. Antrhopology amog the science. «American Antrhopologist», 63 (1961) 475-482. 